\title{
บUsisersily
}

\section{Bonding configurations in amorphous carbon and nitrogenated carbon films synthesised by femtosecond laser deposition}

Roy, SS., Papakonstantinou, P., McCann, R., McLaughlin, JAD., Klini, A., \& Papadogiannis, N. (2004). Bonding configurations in amorphous carbon and nitrogenated carbon films synthesised by femtosecond laser deposition. Applied Physics A, 79(4-6), 1009-1014. https://doi.org/10.1007/s00339-004-2616-z

Link to publication record in Ulster University Research Portal

\section{Published in:}

Applied Physics A

Publication Status:

Published (in print/issue): 01/01/2004

DOI:

10.1007/s00339-004-2616-z

\section{Document Version}

Publisher's PDF, also known as Version of record

\section{General rights}

Copyright for the publications made accessible via Ulster University's Research Portal is retained by the author(s) and / or other copyright owners and it is a condition of accessing these publications that users recognise and abide by the legal requirements associated with these rights.

\section{Take down policy}

The Research Portal is Ulster University's institutional repository that provides access to Ulster's research outputs. Every effort has been made to ensure that content in the Research Portal does not infringe any person's rights, or applicable UK laws. If you discover content in the Research Portal that you believe breaches copyright or violates any law, please contact pure-support@ulster.ac.uk. 

S.S. ROY ${ }^{1}$
P. PAPAKONSTANTINOU ${ }^{1,}$
R. MCCANN ${ }^{1}$
J. MCLAUGHLIN ${ }^{1}$
A. $\mathrm{KLINI}^{2}$
N. PAPADOGIANNIS ${ }^{2}$

\section{Bonding configurations in amorphous carbon and nitrogenated carbon films synthesised by femtosecond laser deposition}

\author{
${ }^{1}$ NIBEC, School of Electrical and Mechanical Engineering, University of Ulster at Jordanstown, \\ Newtownabbey, Co. Antrim BT37 OQB, N. Ireland \\ ${ }^{2}$ FORTH, IESL, P.O. Box 1527, Gr711 10, Crete, Greece
}

\begin{abstract}
Received: 30 September 2003/Accepted: 22 January 2004 Published online: 26 July 2004 • (C) Springer-Verlag 2004

ABSTRACT The effect of nitrogen addition and laser fluence on the atomic structure of amorphous carbon films (a-C) synthesized by femtosecond pulsed laser deposition has been studied. The chemical bonding in the films was investigated by means of X-ray photoelectron (XPS) and Raman spectroscopies. XPS studies revealed a decrease in the $s p^{3}$ bonded carbon sites and an associated increase in the $\mathrm{N}-s p^{2} \mathrm{C}$ bonding sites with increasing nitrogen content in the $\mathrm{CN}_{x}$ films. An increase in laser fluence from 0.36 to $1.7 \mathrm{~J} / \mathrm{cm}^{2}$ led to a rise in $s p^{3} \mathrm{C}$ sites. These results were further confirmed by Raman spectroscopy. The $I_{\mathrm{D}} / I_{\mathrm{G}}$ ratio increased monotonically and $\mathrm{G}$ line-width decreased with the increase of nitrogen content in the films indicating a rise in either the number or the size of the $s p^{2}$ clusters. Furthermore a visible excitation wavelength dependence study established the resonant Raman process in a-C and $\mathrm{CN}_{x}$ films.
\end{abstract}

PACS 81.05.Uw; 81.15.Fg; 82.80

\section{$1 \quad$ Introduction}

It is well appreciated that the energetic nature of laser induced plasma plays an important role in synthesizing certain thermodynamically metastable materials including tetrahedral amorphous carbon ( $\mathrm{t} \alpha-\mathrm{C})$ [1]. So far most of the work $[2,3]$ on pulsed laser deposited a-C and amorphous carbon nitride $\mathrm{CN}_{x}$ film has concentrated on the use of excimer laser or solid state lasers, whose pulse duration is in the nanosecond range. Synthesis of carbon based films by fs lasers is essentially unexplored.

Processing with fs laser pulses offers unique characteristics of minimal thermal damage, fewer particulates and welldefined ablation thresholds. These attributes have been reported in the micromachining (microetching or microdeposition) of fine structures [4]. Only a few [1,5-7] investigations have reported the synthesis of a-C and a- $\mathrm{CN}_{x}$ films by fs lasers. However, those studies were focused mainly on the surface morphology and not on the atomic structure of the films. Motivated from this deficiency of studies, we have investigated the growth and bonding configurations of both a-C and nitrogenated amorphous carbon films produced by a $1 \mathrm{kHz}$, $100 \mathrm{fs} \mathrm{Ti}$ : Sapphire laser.

Fax: +44-28/90-366-863, E-mail: p.papakonstantinou@ulst.ac.uk
XPS and Raman spectroscopy are powerful, non-destructive techniques used in most laboratories for determining bonding structure in all carbon films [8-11]. However, there exist inconsistencies in specifying the effect of Nitrogen on Raman parameters of carbon nitride films due to the different analysis techniques employed. In this report, we present for the first time a comparative study of the $I_{\mathrm{D}} / I_{\mathrm{G}}$ ratio and $\mathrm{G}$ width of $\mathrm{CN}_{x}$ films, using 633 and $514 \mathrm{~nm}$ visible excitation wavelengths.

2

\section{Experimental}

Carbon nitride films were produced by PLD on HF etched, $P$-type silicon, at room temperature. A Ti : Sapphire laser (wavelength $800 \mathrm{~nm}$ ) with a repetition rate of $1 \mathrm{kHz}$ and a pulse duration of $50 \mathrm{fs}$ was used to ablate a graphite target (purity 99.999\%). The focused laser beam was incident at an angle of $45^{\circ} \mathrm{C}$ to the target normal. Two series of experiments were performed. One experiment was for investigating the effect of nitrogen pressure, and the other for investigating the effect of laser fluence in the structure of the films. In the first series, the laser fluence was set at $0.64 \mathrm{~J} / \mathrm{cm}^{2}$ and the chamber was evacuated down to approximately $1 \times 10^{-5}$ mbar prior to each deposition. Nitrogen gas was introduced into the system using a mass flow controller. The target to substrate distance was approximately $4 \mathrm{~cm}$. In the second series of experiments the laser fluence was varied from $0.36 \mathrm{~J} / \mathrm{cm}^{2}$ to approximately $2.12 \mathrm{~J} / \mathrm{cm}^{2}$ without introducing nitrogen into the chamber. The thickness of the films were determined using AFM at a step region created by a photoresist mask.

The carbon and nitrogen bonding configurations and chemical compositions were determined by core level XPS and Raman spectroscopies [8-11]. The XPS measurements were carried out using a non-monochromated $\mathrm{Mg} K_{\alpha}$ $(1253.6 \mathrm{eV}) \mathrm{X}$-ray source, a hemispherical electron energy analyser and a XSAM 800 (Kratos) spectrometer. Ideally, sputter etching is used for cleaning before XPS analysis. In this study all the spectra were recorded without a preceding sputter step. An ISA Labram 300 Raman spectroscope equipped with $\mathrm{Ar}$ ion laser $(514.5 \mathrm{~nm})$ and $\mathrm{He}-\mathrm{Ne}$ laser $(633 \mathrm{~nm})$ was used to examine the structure of the films. The laser power on the sample for both wavelengths was $5 \mathrm{~mW}$ and the spectra being taken over a 20 -s period. 


\subsection{X-ray photoelectron spectroscopy}

XPS analysis was used to determine the chemical composition and relative concentration of chemical bonding configurations in the films. For the samples prepared as a function of laser fluence, the C 1's envelopes were fitted with a mixture of Gaussian and Lorentzian peaks. We found that three peaks gave the best fit to the data. These were located at binding energies of $284.4 \pm 0.2$, (C1) $285.2 \pm 0.2$ (C2), and $287.6 \pm 0.2 \mathrm{eV}$ (C3) $[9,12-14]$ and were assigned to $\mathrm{C}=\mathrm{C}$ ( $s p^{2}$ bonding), $\mathrm{C}-\mathrm{C}\left(s p^{3}\right.$ bonding), and $\mathrm{C}-\mathrm{O}$ respectively. Figure 1 shows representative deconvoluted spectra of the $\mathrm{C}$ 1 's envelopes for films prepared at two different laser fluences of 0.36 and $1.7 \mathrm{~J} / \mathrm{cm}^{2}$.

However in the case of samples prepared as a function of nitrogen pressure, an additional peak located at $286.6 \pm 0.2 \mathrm{eV}$ (C4) was used in the fitting of C 1's envelope to take into consideration the $\mathrm{CN}$ bonding. Figure 2a and $\mathrm{b}$ present the deconvolution of C1's and $\mathrm{N}$ 1's envelopes for two films with 8.87 at. \% and 14.14 at. \% nitrogen respectively. The $\mathrm{N} 1$ 's envelopes were also fitted with three Gaussian/Lorentzian peaks representing $\mathrm{C}-\mathrm{N}\left(s p^{3}\right.$ bonding $)$, $\mathrm{C}=\mathrm{N}$ ( $s p^{2}$ bonding) and $\mathrm{N}-\mathrm{O}$ bonds. The binding energies of these three peaks were located at $398.6 \pm 0.2$ (N1), $399.7 \pm 0.2(\mathrm{~N} 2)$ and $401.5 \pm 0.2 \mathrm{eV}(\mathrm{N} 3)$ respectively.

In the literature there is no unanimity regarding the assignment of first two peaks $[8,15]$. However there is general consensus that the low energy peak $(398.6 \mathrm{eV})$ is related to $\mathrm{C}-\mathrm{N}$ bonds or $\mathrm{C} \equiv \mathrm{N}$, while the high-energy peak is attributed to $\mathrm{C}=\mathrm{N}[8,15]$. The interpretation of our spectra is in agreement with the majority of the literature. For our films we disregarded the assignment of the $\mathrm{C} \equiv \mathrm{N}$ bonds peak, as they were not identified by the visible Raman analysis, which implies that there is no significant amount of $\mathrm{C} \equiv \mathrm{N}$ bonds. Table 1 and 2 show the binding energy positions and relative concentrations of bonding types that contribute to the XPS C 1 's and $\mathrm{N} 1$ 's envelopes respectively.

The XPS analysis of C 1's peaks of the samples prepared at different laser fluences showed that $\mathrm{C} 1$ 's peak position remained nearly constant at $285.4 \mathrm{eV}$. C 1's peak of the sample prepared under the lowest fluence exhibited a narrow asymmetric shape. As the fluence was increased the C 1's peaks became more regular and symmetric (see Fig. 1). From table I we can see that a raise in laser fluence up to $1.7 \mathrm{~J} / \mathrm{cm}^{2}$ causes an increase in the $s p^{3}-\mathrm{C}$ content up to a maximum of $60 \%$ and

\begin{tabular}{lccc}
\hline $\begin{array}{l}\text { Fluence } \\
\left(\mathrm{J} / \mathrm{cm}^{2}\right)\end{array}$ & $\begin{array}{c}\mathrm{C}=\mathrm{C} \\
284.4 \mathrm{eV}\end{array}$ & $\begin{array}{c}\mathrm{C}-\mathrm{C} \\
285.2 \mathrm{eV}\end{array}$ & $\begin{array}{c}\mathrm{C}-\mathrm{O} \\
286.7 \mathrm{eV}\end{array}$ \\
\hline 0.36 & 43.8 & 45.8 & 10.4 \\
0.90 & 37.2 & 52.8 & 10.5 \\
1.04 & 35.3 & 54.0 & 10.7 \\
1.27 & 32.7 & 55.7 & 11.3 \\
1.70 & 27.5 & 60.4 & 12.1 \\
2.12 & 29.0 & 58.4 & 12.2 \\
\hline
\end{tabular}

TABLE 1 Binding energy positions and the relative concentration (\%) of bonding types contributing to the XPS C 1's envelopes as a function of laser fluence

\begin{tabular}{|c|c|c|c|c|}
\hline \multicolumn{5}{|c|}{$\mathrm{N} 1 \mathrm{~s}$} \\
\hline $\begin{array}{l}\mathrm{N} \text { pressure } \\
\text { (mbar) }\end{array}$ & $\begin{array}{l}\mathrm{N} \\
\text { at. } \% \text { in films }\end{array}$ & $\begin{array}{c}\mathrm{C}-\mathrm{N} \\
398.5 \mathrm{eV}\end{array}$ & $\begin{array}{c}\mathrm{C}=\mathrm{N} \\
399.7 \mathrm{eV}\end{array}$ & $\begin{array}{c}\mathrm{N}-\mathrm{O} \\
401.5 \mathrm{eV}\end{array}$ \\
\hline 0.01 & 4.30 & 53.1 & 41.0 & 5.9 \\
\hline 0.05 & 8.87 & 50.6 & 42.4 & 7.0 \\
\hline 0.11 & 14.14 & 39.0 & 51.0 & 10.0 \\
\hline 0.70 & 17.33 & 35.1 & 50.6 & 14.3 \\
\hline
\end{tabular}

TABLE 2 Binding energy positions and the relative concentration (\%) of bonding types contributing to the XPS N 1's envelopes as a function of nitrogen pressure

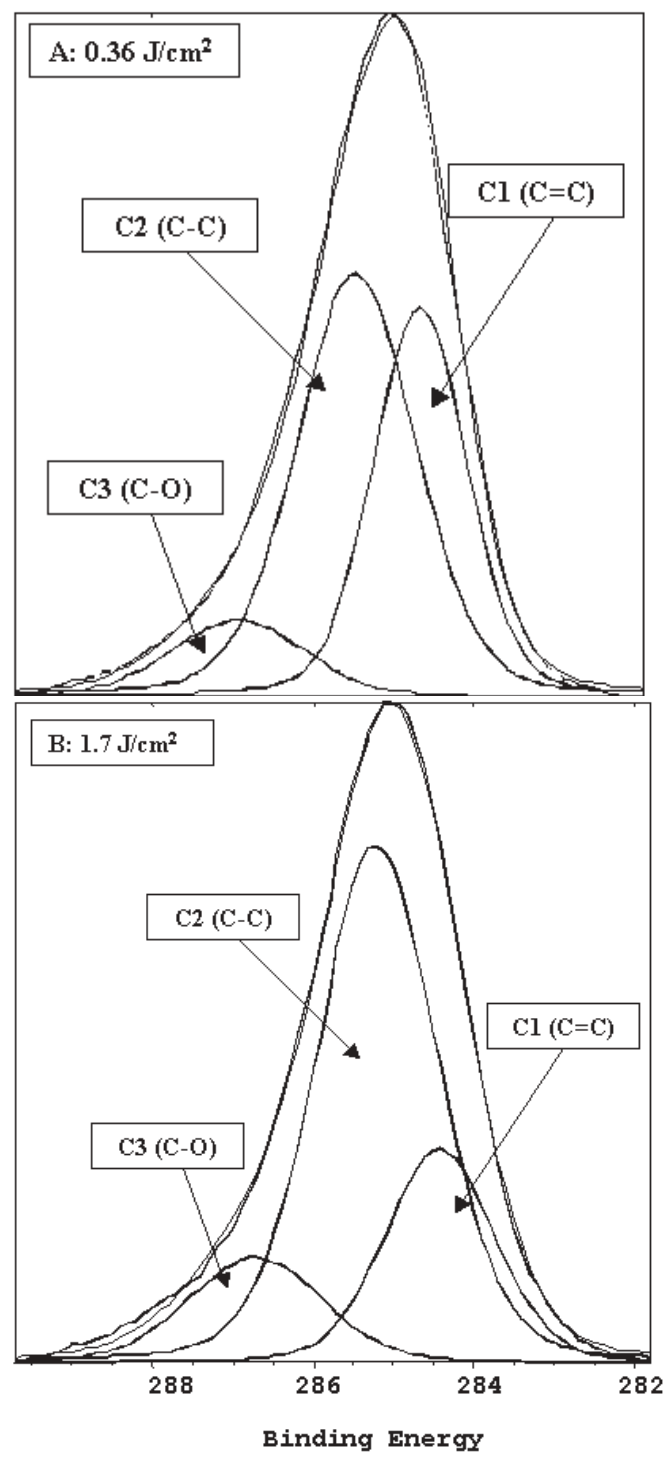

FIGURE 1 Deconvoluted spectra of a-C films prepared at two different of laser fluences

a simultaneous decrease in the $s p^{2}$-C bonds. Further increase in laser fluence $\left(2.12 \mathrm{~J} / \mathrm{cm}^{2}\right)$ resulted in a minor decrease in the $s p^{3}$-C content.

The analysis of the $\mathrm{C} 1$ 's peaks of a- $\mathrm{CN}_{x}$ films revealed that the peaks became broader and more asymmetric as the nitrogen content in the films increased (Fig. 2a). It is also clear from Fig. 2a that the $\mathrm{C} 4$ peak becomes more intensive with the increase of nitrogen content in films. The analysis of $\mathrm{N}$ 1 's peaks also revealed that the peaks became more symmet- 


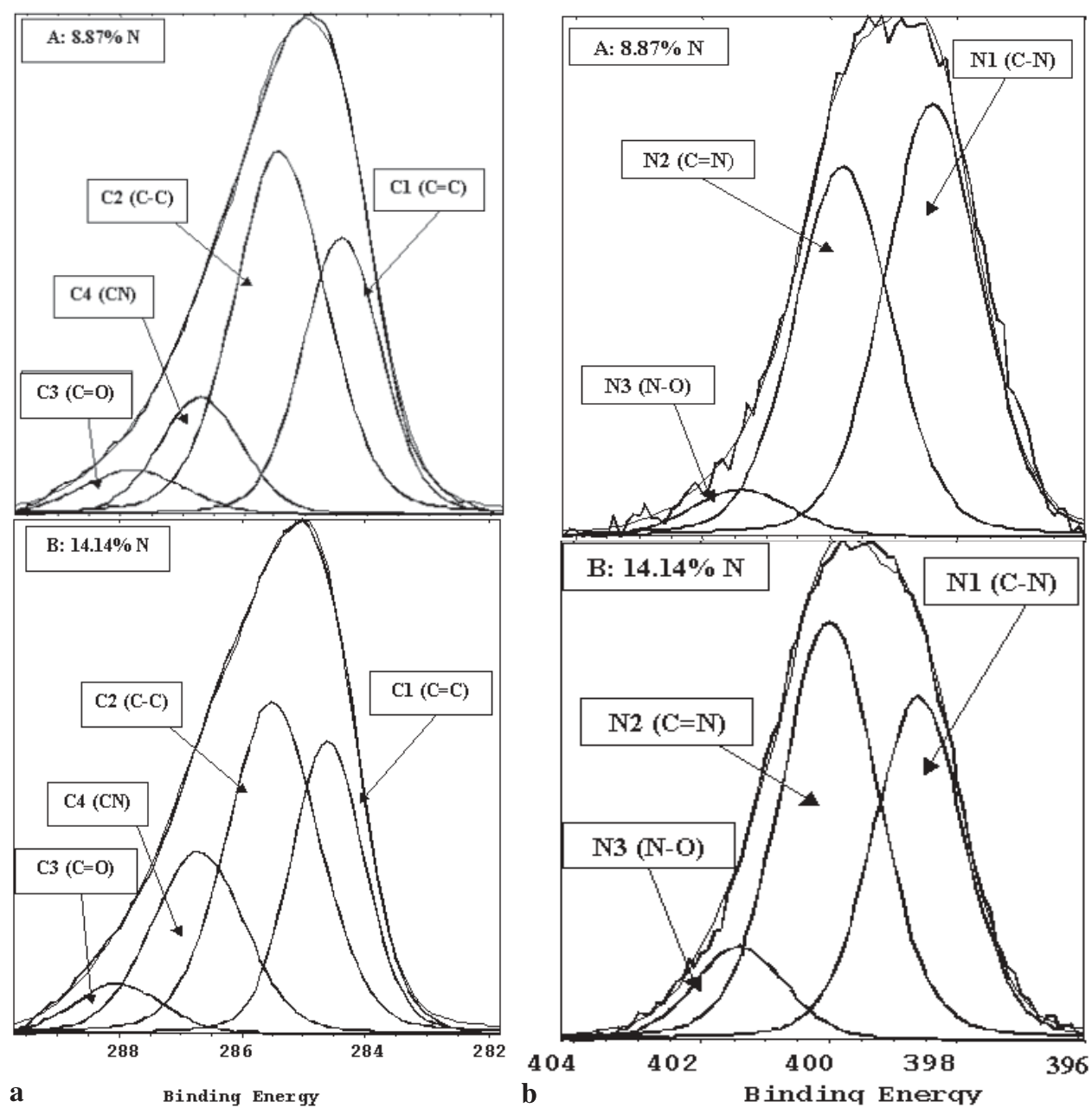

FIGURE 2 a Deconvoluted C 1's spectra of two a- $\mathrm{CN}_{x}$ films prepared under different nitrogen concentrations. b Deconvoluted N 1's spectra of two a-CN $\mathrm{CN}_{x}$ films prepared under different nitrogen concentrations

Binding Energy b

Binding Enercy

ric as the nitrogen content in the films increased (Fig. 2b). Table 2 shows the results of the curve fittings for $\mathrm{N} 1$ 's peaks at different nitrogen pressures. Various points are worth emphasizing from this table. The first one is that the nitrogen content in the films increased progressively with nitrogen pressure. The second one is that as the nitrogen content in the sample increases, the $\mathrm{C}-\mathrm{N}$ bonds $\left(\mathrm{N}-s p^{3} \mathrm{C}\right.$ bonds) decrease, and the $\mathrm{C}=\mathrm{N}$ bonds $\left(\mathrm{N}-s p^{2} \mathrm{C}\right.$ bonds $)$ increase, indicating that the films become more graphite like. In addition to carbon and nitrogen, oxygen was detected within the samples as a minor contaminant. The presence of oxygen can be partly explained due to the prolonged exposure of the samples to the laboratory atmosphere.

\section{2}

\section{Raman spectroscopy}

Depending on the $s p^{3} / s p^{2}$ ratio of carbon bonds, the visible Raman spectra of nitrogen free carbon films show a single asymmetric $G$ peak or two peaks (G peak and D peak) in the $1100-1800 \mathrm{~cm}^{-1}$ region $[10,11]$. The $\mathrm{G}$ peak is connected to the presence of all $s p^{2}$ structures, both olefinic (chains) and aromatic (rings), while the D peak is related to the presence of aromatic rings only [11]. Incorporation of nitrogen in the films creates $\mathrm{CN}$ and $\mathrm{NN}$ bonds at the expense of $\mathrm{CC}$ bonds. Apart from vibration frequencies of $s p^{1} \mathrm{CN}$ bonds all other $\mathrm{CN}$ vibration modes lie within the range of $\mathrm{G}$ and $\mathrm{D}$ bands. So in the $\mathrm{D}-\mathrm{G}$ region, it is impossible to distinguish modes due to $\mathrm{C}$ or $\mathrm{N}$ atoms

So far the Raman spectra of carbon nitride films are decomposed using three different approaches, which has generated confusion. The first one $[8,16]$, arguably the most widely reported one, is based on deconvolution of the $\mathrm{D}-\mathrm{G}$ region into two Gaussian distribution functions. The second $[10,11]$ one is based on a BWF and a Lorenzian shape fitting for the G and $\mathrm{D}$ bands respectively. The third approach [17] uses three Gaussian line shapes attributed to D, G and N bands respectively. In this report, we will not consider the third approach, as we have not observed a distinct third band in the $\mathrm{D}-\mathrm{G}$ region. Instead, we will employ the first and second methods.

Normalized Raman spectra as a function of nitrogen concentration are presented in Fig. 3. It is well known that the growth rate decreases as a function of the nitrogen background pressure, producing variations in the thickness of the $\mathrm{CN}_{x}$ films, grown under the same deposition time. This variation in the thickness produces changes on the Raman intensity. We have normalized our spectra before any fitting. The usefulness of normalizing a set of spectra is that one can visualize changes in the shape and position of the D and G bands as a function of nitrogen concentration and a trend of the Raman parameters can be drawn.

In Fig. 3, the shape of the spectra changes and become more asymmetric as $\mathrm{N}$ at. \% in the film increases. Signifi- 


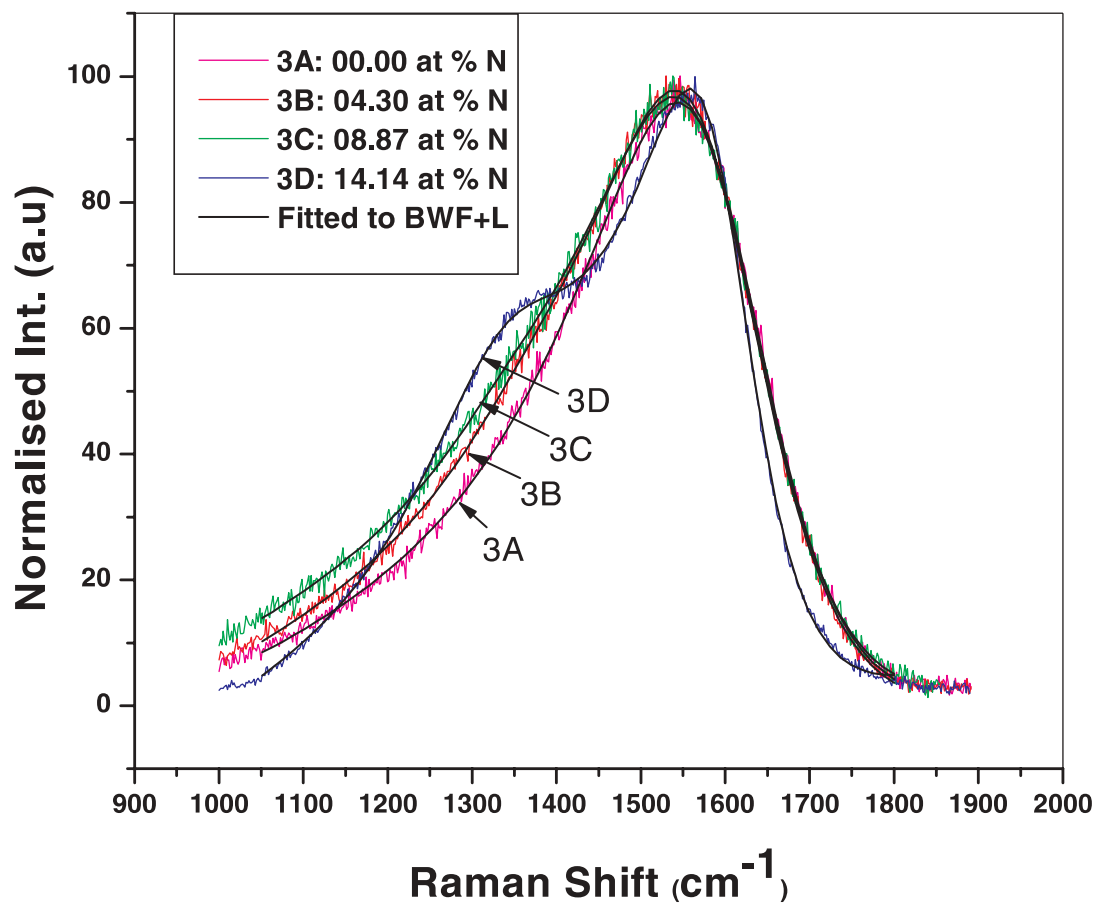

FIGURE 3 Normalized Raman spectra of four $\mathrm{CN}_{x}$ films measured at $514 \mathrm{~nm}$ excitation fitted with $\mathrm{BWF}+\mathrm{L}$ lineshapes

cant changes occurred near the $\mathrm{D}$ peak position. The $\mathrm{D}$ peak was prominent in films with nitrogen concentration higher than 10 at. $\% \mathrm{~N}$ indicating a higher $s p^{2}$ content. In order to make an approximate estimation of the $s p^{3} / s p^{2}$ ratio all the spectra were fitted by a BWF plus a Lorentzian function [10]. In this present study we fitted the data in the range of $1050-1800 \mathrm{~cm}^{-1}$. According to Gilkes et al. [10] a BWF coupling coefficient $(Q)$ lower than -10 implies an $s p^{3}$ fraction greater than $70 \%$. In all of our films $Q$ was greater than -10 implying a $s p^{3}$ fraction less than $70 \%$.

The spectra were also fitted with two Gaussian peaks for $\mathrm{G}$ and $\mathrm{D}$ bands. The Raman parameters obtained from the fittings using $514 \mathrm{~nm}$ excitation wavelength are shown in Fig. 4 whereas the parameters obtained using $633 \mathrm{~nm}$ excitation wavelength are listed in Table 3 . As the $\mathrm{N}$ content in the film increases up to 14.14 at. $\%$ the $I_{\mathrm{D}} / I_{\mathrm{G}}$ ratio increases monotonically and the G peak width decreases (see Fig. 4 and Table 3).

The increase of $I_{\mathrm{D}} / I_{\mathrm{G}}$ ratio and the reduction of the $\mathrm{G}$ linewidth of the nitrogenated carbon films in the present experiment are in agreement with the previous works and indicates an increase in $s p^{2}$ content $[8,16]$. The fall of $I_{\mathrm{D}} / I_{\mathrm{G}}$ ratio and the increase of the $\mathrm{G}$ peak width at the highest $\mathrm{N}$

\begin{tabular}{rcc}
\hline & \multicolumn{2}{c}{ Raman 633 nm } \\
& $I_{\mathrm{D}} / I_{\mathrm{G}}$ & $\mathrm{G}$ width \\
\hline 0.00 & 0.65 & 195.1 \\
1.26 & 0.73 & 190.2 \\
1.60 & 0.76 & 189.0 \\
4.30 & 0.77 & 185.3 \\
8.87 & 1.06 & 161.8 \\
14.14 & 1.14 & 154.8 \\
17.33 & 0.95 & 163.1 \\
\hline
\end{tabular}

TABLE 3 Fitted values $I_{\mathrm{D}} / I_{\mathrm{G}}$ ratio and $\mathrm{G}$ line width in the a-C films, prepared by different laser fluence and measured at $633 \mathrm{~nm}$ excitations

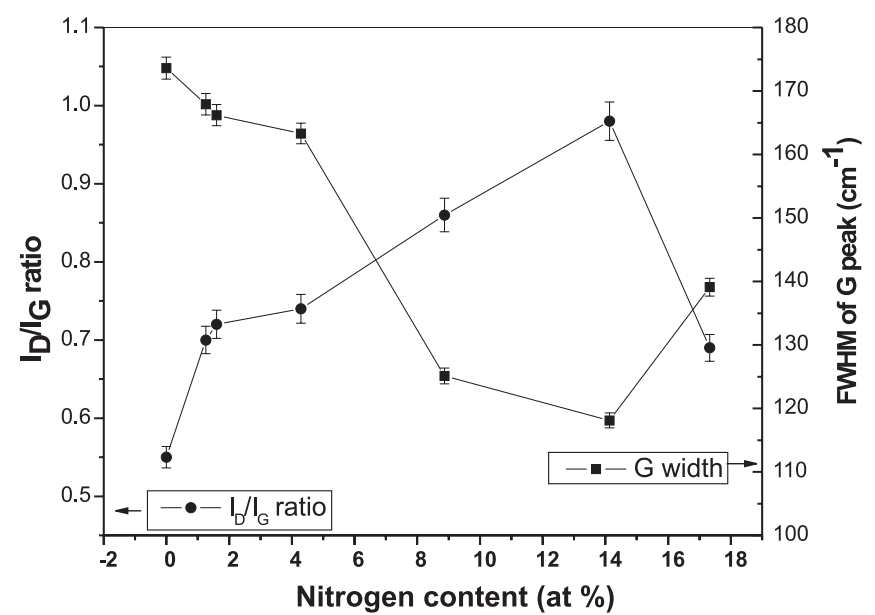

FIGURE $4 I_{\mathrm{D}} / I_{\mathrm{G}}$ ratio and FWHM of the G peak measured with $514 \mathrm{~nm}$ excitation wavelength as a function of nitrogen content

content film (17.33 at. \%) are mainly attributed to the larger cluster size [8]. G peak position did not have a well-defined trend with the increase of $\mathrm{N}$ at. \%. The $\mathrm{D}$ band (D for disorder) around $1360 \mathrm{~cm}^{-1}$ is attributed to the bond angle disorder in the graphite like microdomains, induced by the linking with the $s p^{3}$ carbon atoms; the finite crystalline size of $s p^{2}$ nanodomains as well as substitutional $\mathrm{N}$ atoms and other impurities [8]. Thus, the intensity of the D band is quite sensitive to the size of crystalline microdomains. It seems that $\mathrm{N}$ atoms play a significant role in $s p^{2}$ hybridized $\mathrm{C}$ network. $\mathrm{N}$ atoms are incorporated either by substituting $\mathrm{C}$ atoms in the aromatic rings or connecting these $s p^{2}$ microdomains [18]. The increase in $s p^{2}$ cluster size with $\mathrm{N}$ was in agreement with a reduction in hardness and Young modulus of the films as evaluated by nanoindentation studies. At higher nitrogen pressure the size of the $s p^{2}$ cluster is enhanced and the rigidity of the carbon network is remarkably 


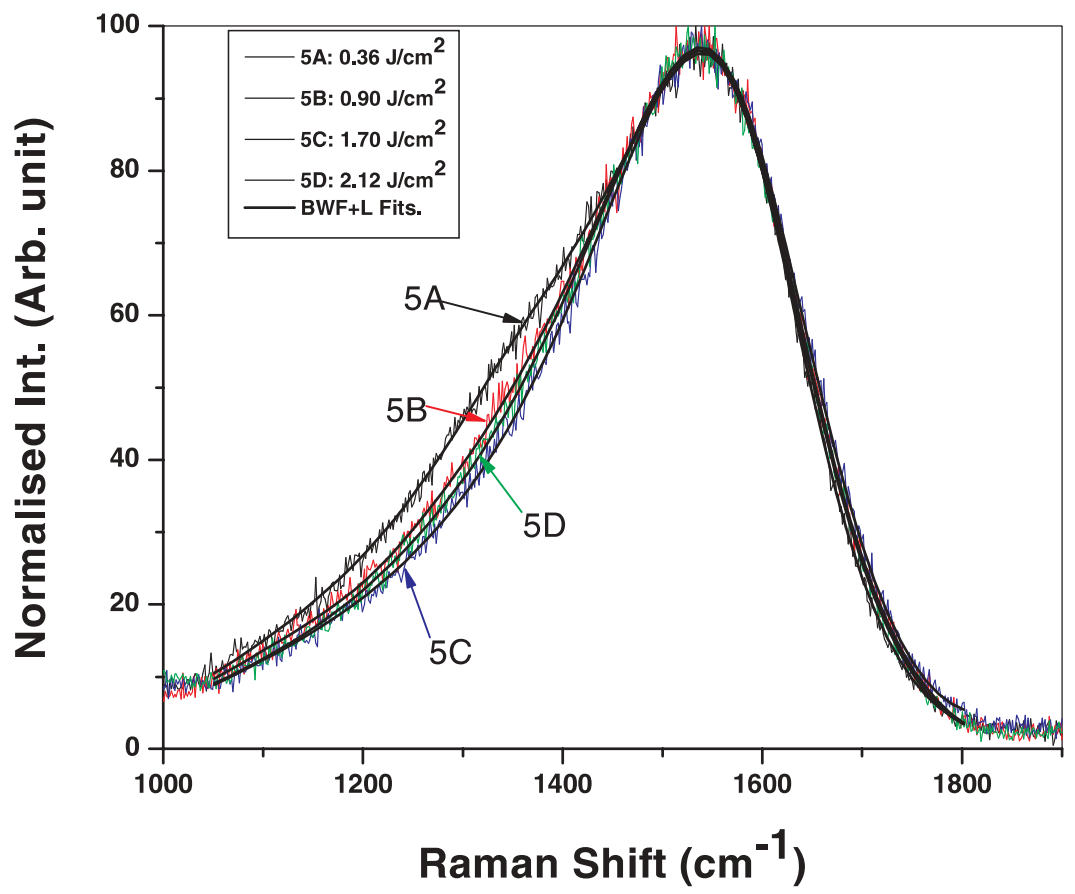

FIGURE 5 Normalized Raman spectra of four representative a-C films prepared by various laser fluence and measured at $514 \mathrm{~nm}$ excitation fitted with $\mathrm{BWF}+\mathrm{L}$ lineshapes

\begin{tabular}{lcc}
\hline $\begin{array}{l}\text { Fluence } \\
\left(\mathrm{J} / \mathrm{cm}^{2}\right)\end{array}$ & \multicolumn{2}{c}{ Raman 633 nm } \\
\hline 0.36 & $I_{\mathrm{D}} / I_{\mathrm{G}}$ & G width \\
0.90 & 0.90 & 184.2 \\
1.04 & 0.77 & 187.2 \\
1.27 & 0.68 & 191.9 \\
1.70 & 0.66 & 194.1 \\
2.12 & 0.57 & 198.5 \\
\hline
\end{tabular}

TABLE 4 Fitted values $I_{\mathrm{D}} / I_{\mathrm{G}}$ ratio and $\mathrm{G}$ line width at different level of nitrogen in the $\mathrm{CN}_{x}$ films, measured at $633 \mathrm{~nm}$ excitations

reduced. The relation for estimating the size of ordered regions from the $I_{\mathrm{D}} / I_{\mathrm{G}}$ ratio in the Raman spectra of carbon is as follows [19]:

$\frac{I_{\mathrm{D}}}{I_{\mathrm{G}}}=C(\lambda) L_{a}^{2}$,

where $C$ is a constant having a value of approximately 0.0055 at $514.5 \mathrm{~nm}$ and $L_{a} \quad(\leqslant 20 \AA)$ is a linear dimension of the ordered region. The cluster size as calculated from (1) varied from $10 \AA$ to $13.35 \AA$ as the $\mathrm{N}$ content in the films changed from 0 to 14.14 at. \%. Ferrari et al. [11] have previously reported that FWHM of G band decreases continuously as the disorder increases. Hence, we may infer from Fig. 4 and Table 3 that the lowering of FWHM of G band with $\mathrm{N}$ content indicates an increase of cluster size and which support our previous calculation. The increase of cluster size at higher $\mathrm{N}$ content films is attributed to the thermalization of the laser ablated species, leading to the formation of structures with reduced three dimensional cross linking.

Some representative Raman spectra of carbon films deposited at different laser fluence are shown in Fig. 5.

Raman parameters calculated from the fittings are listed in Fig. 6 (514 nm excitation wavelength) and Table 4 (633 nm excitation wavelength). The $\mathrm{G}$ peak became more symmet-

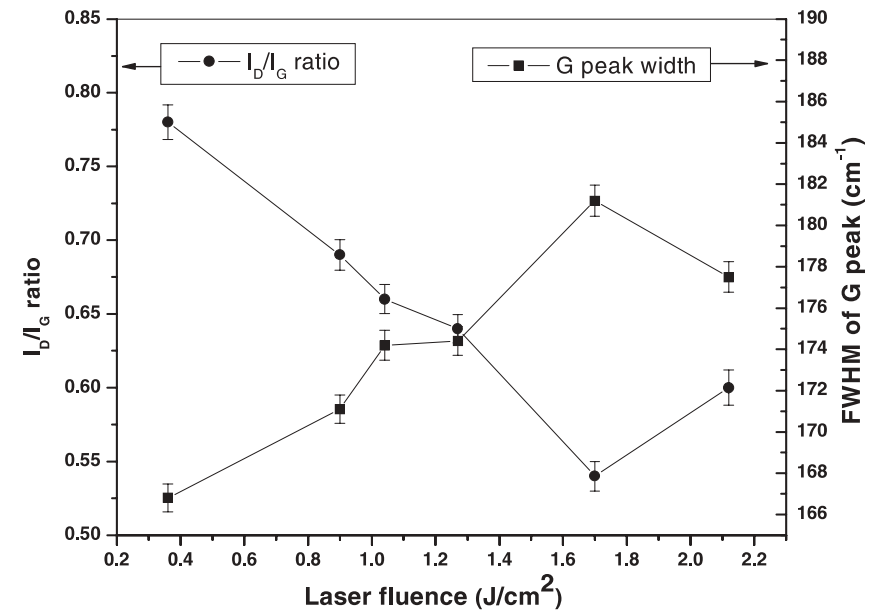

FIGURE $6 I_{\mathrm{D}} / I_{\mathrm{G}}$ ratio and FWHM of $\mathrm{G}$ peak position measured with $514 \mathrm{~nm}$ excitation wavelength as a function of laser fluence

ric with the increase of laser fluence up to $1.7 \mathrm{~J} / \mathrm{cm}^{2}$, which indicates an increase of $s p^{3}$ content. Above $1.7 \mathrm{~J} / \mathrm{cm}^{2}$ the $\mathrm{G}$ peak becomes less symmetric. The skewness of the $\mathrm{G}$ line shape $(Q)$ was evaluated using a BWF and a Lorentzian function. As the laser fluence increased from $0.36 \mathrm{~J} / \mathrm{cm}^{2}$ to $1.7 \mathrm{~J} / \mathrm{cm}^{2}$ the $Q$ parameters decreased from -1.5 to -3.5 and at $2.12 \mathrm{~J} / \mathrm{cm}^{2} Q$ parameter was found to be -2.8 . In addition as the laser fluence increased, the $I_{\mathrm{D}} / I_{\mathrm{G}}$ ratio decreased to a minimum value and then rose again. The $I_{\mathrm{D}} / I_{\mathrm{G}}$ ratio, $\mathrm{G}$ width and $Q$ parameter value suggest that there is an optimum laser fluence for the growth of films, with a high percentage of $s p^{3}$ bonds and when it is surpassed the $s p^{3}$ bonds stop raising.

It is expected that the kinetic energy of plasma species to increase with the increase of laser fluence. Although a high kinetic energy (tens to several hundreds of eV) [19] is favorable for the formation of $s p^{3}$ bonding, excessive particle energies ( $\mathrm{keV}$ regime) are detrimental to the film quality 


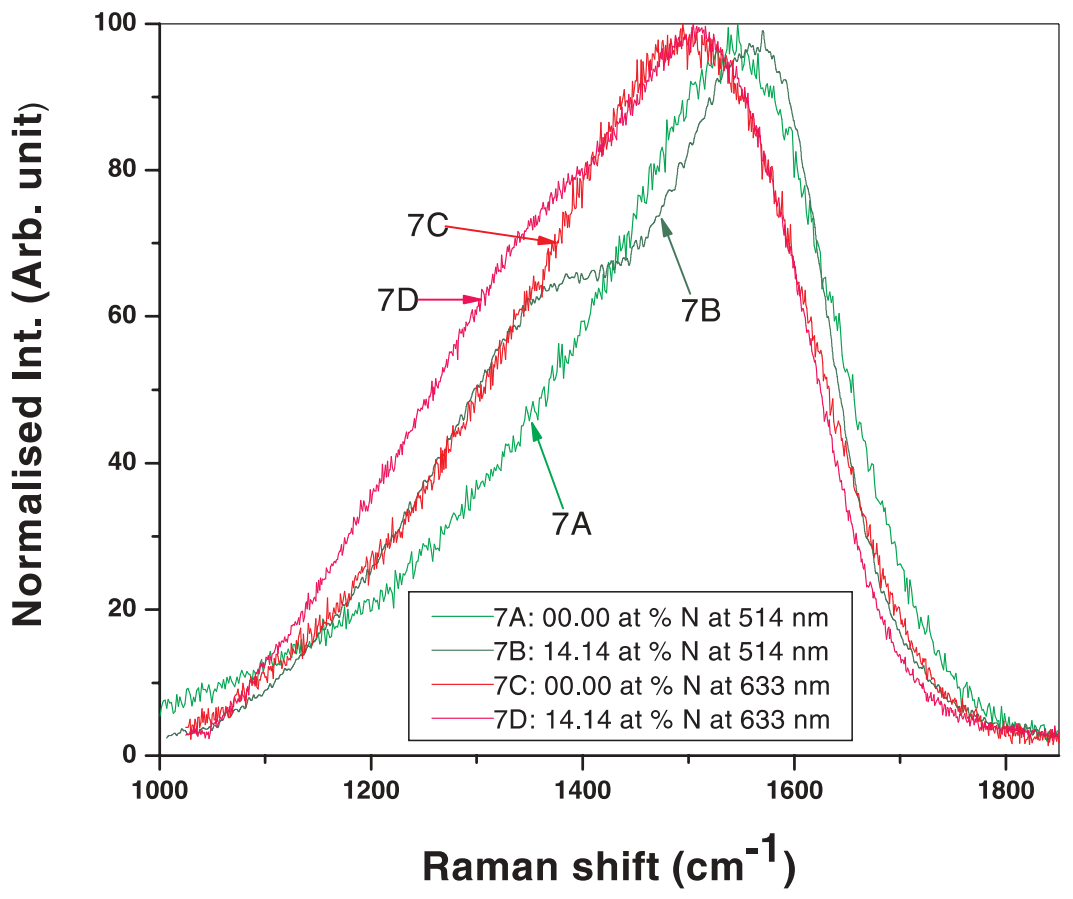

FIGURE 7 Normalized Raman spectra of two films with 0 at. $\% \mathrm{~N}$ and 14.14 at. $\% \mathrm{~N}$, measured at 514 and $633 \mathrm{~nm}$ excitations and are responsible for pushing the resultant films into the graphitic regime $[6,19]$. We believe that the plasma formed at $2.12 \mathrm{~J} / \mathrm{cm}^{2}$ exhibits two contributions with a fast moving suprathermal ion component preceding a majority of slower thermal ions as identified in previous studies [6]. These suprathermal ions are responsible for introduction of $\sigma$ and $\pi$ defects in the films leading to an increase in the $I_{\mathrm{D}} / I_{\mathrm{G}}$ ratio. The Raman parameters shown in Fig. 6 and Table 4 strongly agree with the XPS results.

It is well known that Raman line shape of any carbon films depends on laser wavelength. The band gap of any carbon film depends on the bonding configuration in the films. Raman scattering from all forms of carbon is generally a resonant process, in which configurations whose band gaps match the excitation energy are preferentially excited. Variations of Raman parameters with excitation wavelength can be observed from Fig. 4 and Table 3. Three points are worth mentioning from Figs. 7, 4 and Table 3: i) G positions are lower at higher wavelength (see Fig. 7). ii) The FWHM of the G line when measured with the $633 \mathrm{~nm}$ laser were higher compared to the $514 \mathrm{~nm}$ laser. iii) The shape of the $\mathrm{G}$ lines were more symmetric at $514 \mathrm{~nm}$ laser compared to $633 \mathrm{~nm}$ laser. Also the $I_{\mathrm{D}} / I_{\mathrm{G}}$ ratio increased at the higher excitation laser wavelength.

The above observations are consistent with previous work [11]. For a fixed wavelength, the $I_{\mathrm{D}} / I_{\mathrm{G}}$ ratio increased with $\mathrm{N}$ at. $\%$ as the $s p^{2}$ content or $s p^{2}$ cluster within the $s p^{3}$ matrix increased. On the other hand, for a fixed $\mathrm{N}$ at. \% films, the $I_{\mathrm{D}} / I_{\mathrm{G}}$ ratio (or relative $\mathrm{D}$ band intensity) also increased at the higher excitation wavelength of $633 \mathrm{~nm}$ as the higher wavelengths excite cluster that have a larger size and smaller band gap. At $514 \mathrm{~nm}(2.41 \mathrm{eV})$ laser wavelength, one can expect an increase in the plane stretching of the bonds compared to $633 \mathrm{~nm}(1.95 \mathrm{eV})$, which in turn increases the $\mathrm{G}$ peak position.
ACKNOWLEDGEMENTS This work was supported by the European Union through the 'Access to research infrastructures programme', at the Institute of Electronic Structure and Laser Applications in Crete.

\section{REFERENCES}

1 A.S. Loir, F. Garrelie, J.L. Subtil, F. Goutaland, M. Belin, R. Le Harxic, C. Donnet, Y. Ouerdane, F. Rogemond P. Laporte: Appl. Surf. Sci. 208209, 553 (2003)

2 K.J. Koivusaari, J. Levoska, S. Leppavuori: J. Appl. Phys 85, 2915 (1999)

3 Z.Y. Chen, J.P. Zhao, T. Yano, T. Ooie: J. Appl. Phys 92, 281 (2002)

4 P. Papakonstantinou, N.A. Vainos, C. Fotakis: Appl. Surf. Sci. 151, 159 (1999)

5 Zs. Geretovszky, Z. Kántor, T. Szőrényi: Appl. Surf. Sci. 208-209, 547 (2003)

6 F. Qian, V. Craciun, R.K. Singh, S.D. Dutta, P. P Pronko: J. Appl. Phys. 86, 2281 (1999)

7 Z. Geretovszky, Z. Kántor, I. Bertóti, T. Szőrényi: Appl. Phys. A 70, 9 (2000)

8 P. Papakonstantinou, P. Lemoine: J. Phys.: Condens. Matter 13, 2971 (2001)

9 P. Merel, M. Tabbal, M. Chaker, S. Moisa, J. Margot: Appl. Surf. Sci. 136, 105 (1998)

10 K.W.R. Gilkes, S. Prawer, K.W. Nugent, J. Robertson, H.S. Sands, Y. Lifshitz, X. Shi: J. Appl. Phys. 87, 7283 (2000)

11 A.C. Ferrari, S.E. Rodil, J. Robertson: Phys. Rev. B 67, 155306 (2003) and reference therein.

12 S.F. Muhl, J.M. Mendez: Diamond Relat. Mater. 8, 1809 (1999)

13 N. Hellgren, M.P. Johansson, E. Broitman, L. Hultman, J.E. Sundgren: Phys. Rev. B 59, 5162 (1999)

14 N. Hellgren, J. Guo, C. Sathe, A. Agui, J. Nordgren, Y. Luo, H. Ågren, J. Sundgren: Appl. Phys. Lett. 79, 4348 (2001)

15 W.T. Scarf, D. Rott, D Yang, A.J. Barnard: J. Appl. Phys. 85, 3142 (1999)

16 J.R. Shi, J.P. Wang, A.T.S. Wee, C.B. Yeo, C.T. Cheng, M. Ueda, S. Tomioka, J. Ohsako: J. Appl. Phys. 92, 5966 (2002)

17 D. Das, K.H. Chen, S. Chattopadhyay, L.C. Chen: J. Appl. Phys. 91, 4944 (2002)

18 J.C. Sánchez-López, C. Donnet, F. Lefèbvre, C. Fernández-Ramos, A. Fernández: J. Appl. Phys. 90, 675 (2001)

19 J. Robertson: Mater. Sci. Eng. R37, 129 (2002) 